$\begin{array}{ll}\text { DE DE GRUYTER } & \begin{array}{l}\text { Review of Middle } \\ \text { East Economics } \\ \text { and Finance }\end{array}\end{array}$

\title{
WHAT TO SMOOTH: RATE OF INTEREST OR THE FOREIGN EXCHANGE? TURKISH MONETARY POLICY UNDER TURBULENT TIMES
}

\begin{tabular}{|c|c|}
\hline Journal: & Review of Middle East Economics and Finance \\
\hline Manuscript ID: & DGRMEEF.2014.0036 \\
\hline Manuscript Type: & Research Article \\
\hline Classifications: & E52, E58, F41, F65, 052 \\
\hline Keywords: & $\begin{array}{l}\text { Interest Rate Smoothing, Inflation Targeting, Turkey, Financial Stability, } \\
\text { Credibility }\end{array}$ \\
\hline Abstract: & $\begin{array}{l}\text { This paper studies the new monetary stance of the Central Bank of } \\
\text { Republic of Turkey (CBRT) during the Great Recession. We note that } \\
\text { characteristics of the post-1997 "great moderation" revealed interest rate } \\
\text { smoothing as a valid policy option for the inflation targeting central banks. } \\
\text { Utilizing econometric analyses on a general form of a Taylor Rule, we } \\
\text { search for the relative weights of the objective function of the CBRT over } \\
\text { Jan } 2010 \text { - Dec } 2013 \text {. We find that over the great recession, the CBRT's } \\
\text { focus on "interest smoothing" had been maintained; and yet the burden of } \\
\text { adjustment fell disproportionately on the foreign exchange } \\
\text { markets. Furthermore, weak credibility of the CBRT, lack of a simple policy } \\
\text { rule, and noisy policy communications evidence that pre-requisites of the } \\
\text { interest rate smoothing are not being fulfilled. Inevitable sharp policy } \\
\text { corrections that follow smoothing periods prove insufficient against the } \\
\text { voluminous global flows. }\end{array}$ \\
\hline
\end{tabular}

\section{SCHOLARONE ${ }^{\text {Mx }}$ \\ Manuscripts}




\begin{abstract}
This paper studies the new monetary stance of the Central Bank of Republic of Turkey (CBRT) during the Great Recession. We note that characteristics of the post-1997 "great moderation" revealed interest rate smoothing as a valid policy option for the inflation targeting central banks. Utilizing econometric analyses on a general form of a Taylor Rule, we search for the relative weights of the objective function of the CBRT over Jan 2010 - Dec 2013. We find that over the great recession, the CBRT's focus on "interest smoothing" had been maintained; and yet the burden of adjustment fell disproportionately on the foreign exchange markets. Furthermore, weak credibility of the CBRT, lack of a simple policy rule, and noisy policy communications evidence that pre-requisites of the interest rate smoothing are not being fulfilled. Inevitable sharp policy corrections that follow smoothing periods prove insufficient against the voluminous global flows.
\end{abstract}

Key Words: Inflation Targeting; Interest Rate Smoothing, Monetary Policy, Financial Stability, Credibility, Turkey

JEL Codes: E52, E58, F41, F65, O52

\title{
I. Introduction
}

The art of modern banking is at an impasse. The almost sanctimonious days of inflation targeting (IT) with a primary objective-single instrument ${ }^{1}$ under the bi-polar view ${ }^{2}$ of a freefloating, flexible exchange rate administration are long gone.

Portrayed under the common parlance of Great Moderation, the IT regimes achieved considerable success in reducing both the level and volatility of the rates of inflation at

\footnotetext{
${ }^{1}$ Note, for instance, the Bank of England's policy mandate: "One of the Bank of England's two core purposes is monetary stability (the "other" core purpose is financial stability -authors' note). Monetary stability means stable prices - low inflation- and confidence in the currency. Stable prices are defined by the Government's inflation target, which the Bank seeks to meet through the decisions on interest rates taken by the Monetary Policy Committee. (www.bankofengland.co.uk). (Emphases ours).

${ }^{2}$ Recall the seminal arguments in Fischer, Stanley (2001) "Exchange Rate Regimes: Is the Bipolar View Correct?", Journal of Economic Perspectives, Vol. 15: 3-24.
} 
modestly low sacrifice ratios. As the IT framework deepened and elevated to the status of almost global consensus, the (short term) interest rates came to be regarded as the primary instrument of monetary policy. Given this exclusive focus on price stability via interest rate responses, however, there had been a concomitant common observation that historical responses of the nominal interest rates to shocks had been significantly more gradual and sticky than the optimal policies called for by the efficiency rules generated from intertemporal consumption smoothing (Cass-Koopmans-Ramsey) models. To account for this fact, some authors noted a revealed desire on the part of the IT-central banks to smooth their rates of interest over and beyond the generally stated objective of achieving price stability. ${ }^{3}$

Thus, the aforementioned desire for interest rate smoothing has gradually surfaced out as the main underlying motive of the modern central banks (CBs) under the age of great moderation. Consequently, in an attempt to secure investor confidence and credibility, the CBs came to be increasingly constrained to maintain a constant rate of interest in their operations.

However, global conditions changed abruptly with the eruption of the Lehman Brothers crisis in late 2008, and the generally accepted monetary policy mantras took a severe hit. Fueled with a series of quantitative easing operations and stimulus packages across the advanced economies, the global currency markets turned excessively liquid. One country another, the CBs realized painstakingly how the policy impact of their main policy instrument - the interest rate- has diminished as the zero-lower bound eventually surfaced.

Furthermore, in the developing emerging market economies (EMEs) the CBs faced another dilemma: On the one hand they tried to take advantage of expanded external global finance, while on the other hand they strived to maintain control against excesses of such flows that risk their external balance and financial stability through the credit channel. Concerns over financial stability and currency wars casted their shadow over the interest rate differentials, causing EME central banks more reluctant to apply the interest rate as the main policy instrument. Thus, compared to the days of the great moderation when inflation risks were moderate, objective functions of the IT central banks became rather opaque, while the interest rate as a single, clear tool has been substituted with broader, and unavoidably impervious, macro prudential measures. Noisy communications aggravated these problems.

\footnotetext{
${ }^{3}$ See, e.g., Srour (2001); Lowe and Ellis (1998), Sack (1998a, 1998b) Drew and Plentier (2000), Mehra (2001), Benhabib et. al. (2003), and Woodford (2002) for a detailed analysis of measuring the interest rate smoothing. In its most succinct form, the argument is that monetary authorities are assumed to minimize a loss function of the form: $b_{1} \operatorname{var}\left(y_{t}\right)+b_{2} \operatorname{var}\left(P_{t}\right)+b_{3} \operatorname{var}\left(i_{t}-i_{t-1}\right)$ where $y_{t}$ is real output; $P_{t}$ is the price level; and $i_{t}$ is the interest rate instrument. $\operatorname{Var}\left(\right.$.) denotes the variance of the associated variables, and $b_{1}, b_{2}, b_{3}$ are positive coefficients.
} 
The new framework denounces that many CBs now had to move away from the clear policy prescriptions of a "single objective-single instrument" IT framework. In the immediate aftermath of the Lehman Crises reaction of the CBRT was similarly no different than many other EMs, ie: cutting the interest rates in line with the falling global rate plateau. Meanwhile, macro prudential measures were employed counter cyclically in search for securing financial stability.

Smooth start of the "multi objective - multi instrument" policy was challenged with the European debt crisis, which brought "high frequency monetary policy" as an inevitable policy choice in front of the CBRT due to excessive currency volatility. Yet, we read this as a transition period, the gain of which was relative stability of the exchange rate. One shall note is that the aforementioned period contrasts with the interest rate smoothing. But it does not mark a permanent deviation in the monetary stance of the CBRT due to its transitionary nature. Figure-1 below also clearly exhibits the Bank's choice for interest rate smoothing emerging back as of second quarter of 2013. As soon as the FED tapering woes casted its shadow over the EM currencies, CBRT's interest rate smoothing intention becomes more visible at the expense of currency volatility. Indeed, Erdem Basci's own words that describe the implicit reaction function as "we buy interest rate stability at the expense of exchange rate volatility". (emphases ours) help us rest our case.

This statement by the CBRT, prioritizing the interest rate stability regardless of its cost on the price stability mandate through exchange rate pass-through, clearly is at odds with the conventional IT approach. Yet it is important to be studied as it hints a new objective function of the Bank that is being re-tailored in the post Lehman Crisis Era.

Admittedly, "rule-based" monetary policy is fairly new for the Turkish Central Bank. When the exchange rate-based disinflation program had unsuccessfully terminated in February 2001, Turkish economy experienced a severe crisis, paving the way for free floating currency then after. The stormy days of the crisis triggered a chain of mandatory (not necessarily volunteering) reforms which included an amendment in CBRT Law as of April 2001, giving independence to the Bank. Facing the difficulty of fulfilling the pre-requisites of IT in the immediate short run, CBRT designed a transitional policy period called "Implicit Inflation Targeting" that lasted until 2005.

Formal adoption of the IT came as of 2006. As the great recession culminated after 2008, CBRT initially adopted an "observer" stance, trying to understand and adjust to the post-crisis 
conditions while easing out the conditions of the IT. Seeing the potential adverse impacts of the quantitative easing packages on the emerging markets through the credit channel, CBRT incorporated a new "financial stability" objective into the IT-framework in 2010, which turned into the fuzzy term "IT-plus" in the words of the CBRT Governor Basci. This "multiobjective" stance necessitated a larger tool-box, as the CBRT strengthened its hand with new instruments; i.e, mainly the macro prudential measures.

Yet all these were not free from critiques as the Bank fell short of explaining the roles of different tools in the monetary transmission mechanism, especially while delivering a noisy communication. International institutions such as the IMF, credit rating agencies and financial market players found the new monetary stance opaque -to say the least- despite claims otherwise by the CBRT.

In this paper we try to shed light on the current policy practices of the CBRT given evidence of the de facto interest smoothing attempts embedded into the IT framework. More formally we seek to provide evidence to the following questions: How did the CBRT's policy objectives and strategic instruments evolve since the onset of the great recession? Did the post-QE global conditions lead to a change in the responsiveness of the CBRT to different macroeconomic indicators? In particular, how dominant currently is the smoothing motive for the CBRT given the de facto (not necessarily officially granted) reaction function, and how well has it been maintained?

To this end, we utilize a central bank reaction function framework in the form of an expanded Taylor Rule regression, over Jan 2010-Dec 2013. Here our aim is not to reveal the CBRT's official monetary policy rules per se, but rather to document in an ex post sense the behavior of the CBRT under its official guidelines and responses against the conditionalities imposed by the international finance community. We find that with the onset of the great recession when significant shifts in the macroeconomic environment have occurred, the CBRT's focus on "interest smoothing" had been maintained; and yet the burden of adjustment fell disproportionately on the foreign exchange markets. The CBRT was unavoidably bounded to follow a multi-objectional, discretion-driven policy stance rather than a single-objective monetary rule. Lack of sufficient information on the monetary transmission mechanism coupled with excessively noisy communications compounded problems of credibility.

The remaining pages of the paper are organized in four additional sections. Next, we provide a brief overview of the literature on interest rate smoothing to be followed by a short 
monetary history of Turkey since full-fledged IT. We implement our econometric assessments in section four. Section five summarizes and concludes.

\section{Experiences with Interest Rate Smoothing}

There is now a significant body of accumulated empirical evidence suggesting that CBs tend to change their policy interest rates only gradually; and that, they reveal even greater reluctance to initiate reversals. This tendency of the CBs to change their short-term interest rates in sequences of small steps in the same direction while reversing their direction only infrequently (and reluctantly) has often been labeled as "interest smoothing" (Sack and Wieland, 2000).

It was argued by Lowe and Elis as early as 1998 that the interest rate smoothing strategy has been an important part of central banks policies in the US, Japan and Germany. BIS (1998) reached to a similar conclusion for Italy, France, Canada, Spain, the Netherlands, Belgium, Sweden and Austria. Interest rate smoothing is evident in emerging countries as well. Csermely and Rezessy (2007) documented the smoothing motive for Hungary. Helmi (2011) shows that Jordan, Morocco, Israel and Turkey use interest rate smoothing while managing their monetary policy. In his quarterly analysis over the period 2002 to 4Q2009 he also found out that smoothing coefficient was high in Turkey's reaction function; and that "foreign interest rates play a significant role in setting the interest rate in Turkey". Focusing on CBRT's "implicit inflation targeting” era, Kadioglu (2006) reported that smoothing parameter revealed a higher response than the responses triggered by inflation misses and the output gap. Comert, Yeldan and Olcum (2010), in turn, extended the observation period and studied the interest rate policy of the CBRT in the post financial liberalization and deregulation era (2002-2008), finding that "the Bank's interest rate smoothing tendency is the main determinant of its policy in this period".

Several theoretical explanations had been advanced to account for this phenomenon. The first is based on arguments of attaining and maintaining "credibility" in an uncertain and often volatile world of international finance. Monetary authorities often find it more effective to commit to a given level of its main instrument - the interest rate over extended periods of 
time rather than creating the image that "they are lost in the dark". ${ }^{4}$ In order to reduce the risks associated with open capital accounts, the CBs are often committed to follow simple and well-defined rules in the name of accountability and transparency ${ }^{5}$ and are conditioned by the markets to avoid frequent variations in its instruments that would cause large swings in asset prices and the financial rates of return. Such swings could cause insolvencies in public debt and might have a severe negative impact in the corporate balance sheets. Finally, persisting uncertainties might force central banks to adjust their interest rates only gradually. There are different types of uncertainties that can be used to explain the interest rate smoothing phenomena. Central banks are uncertain about the impacts of their tools on their economies (parametric uncertainty); the state of their economies (modeling uncertainty); the reliability of existing data (data uncertainty), and the characteristic and magnitude of future shocks (Comert, Yeldan, Olcum, 2010).

\section{CBRT Under the Great Recession}

Turkey's bitter experience with the pegged currency drove the country to a mandatory regime change. Already running with an average consumer inflation of $75 \%$ in a decade (1990-2001), sharp depreciation of TL by $64 \%$ after the collapse of the crawling peg (April-February, 2001) added further worries about inflation. Hence seizing the advantage of newly granted independence, CBRT chose to adopt "inflation targeting" as the new monetary regime.

Yet as inflation came down to single digits, challenges in explicit inflation targeting period turned out to be higher with sticky prices, and CBRT was not as successful this time. Indeed, from 2006 to 2008, CBRT exceeded the official inflation targets in each of the three years, bringing Turkey back to double digit year-end inflation as of 2008.

All in all, although Lehman Crisis is marked with low inflation in the world, Turkey can be pointed at as an outlier, with high inflation and the weak IT performance of its central bank. This weak performance combined with the lasting credibility gap show that the Bank does not have much room for comfort regarding the inflation and its associated reaction function.

\footnotetext{
${ }^{4}$ From a different perspective, Caplin and Leahy (1996) advance a similar motivation. They argue that policymakers do not like frequent and sudden interest rate changes because they do not want to give an impression that they are poorly informed.

5 A 2007 study by JP Morgan states, for instance, that "the incremental gain of credibility from central banks' efforts to increase dialogue and accountability is minimal. What really matters in the current conjuncture is maintaining clear and predictable rules for interest rates". JP Morgan, Daily Report, 14 May 2007.
} 


\footnotetext{
${ }^{6}$ For a comprehensive documentation on the enhanced policy tools of the CBRT, see Aysan, Fendoglu and Kilinc (2014); Oduncu, Akcelik and Ermisoglu (2013); Akcelik, Aysan and Oduncu (2013); Kara (2012); Degerli and Fendoglu (2013).

${ }^{7}$ CBRT Presentation, February 2011.
} 
swings in the paths of the rates of interest (funding cost of the CBRT) and that of the foreign exchange (weighted basket). (See Figure 1).

\section{Figure 1}

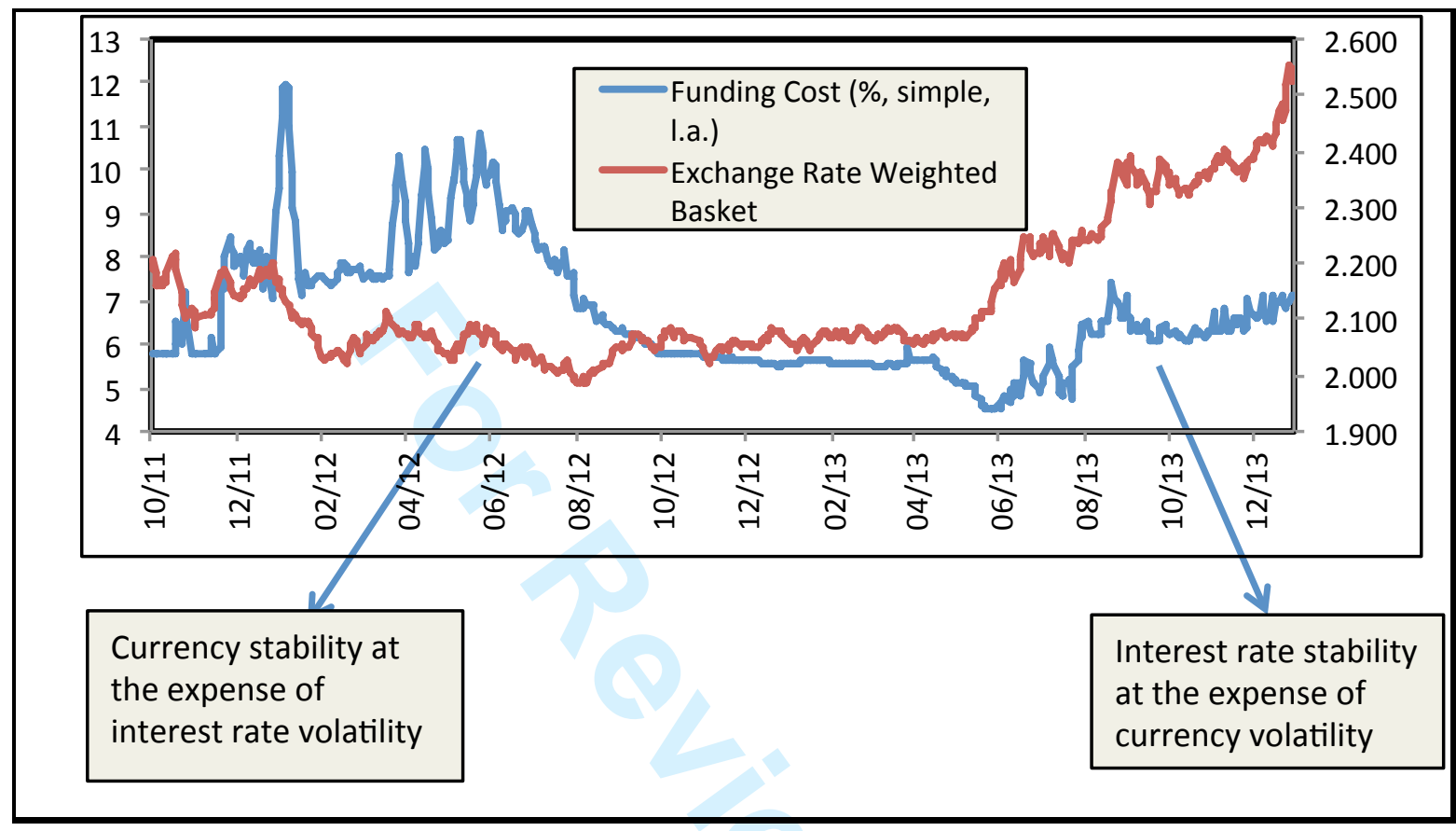

Source: CBRT

It was at this juncture that Mr. Basci summarized the Bank's position succinctly as "buying interest rate stability at the expense of currency volatility". Yet, the existing external deficit of Turkey makes this choice highly risky, delivering fragility to the overall economy. Turkish corporate sector has a short FX position of USD 174 bn as of 2013 (short term: USD 18 bn). Hence volatility in the currency carries the risk of hurting the investment decisions, as well as production costs, and CBRT's tolerance for TL depreciation will inevitably be limited given its negative impact on output as well as price setting. This lack of tolerance sets a certain limit to the smoothing attempts. We attempt to distill the policy responses of the CBRT under these conditions with the aid of an expanded Taylor Rule econometrics next. 


\section{Econometrics of the CBRT's Taylor Rules}

Central banks that operate within a flexible, floating exchange rate regime continuously confront the question of the determinants of their interest rate decisions and associated weights. The so-called Taylor Rule set forth by John B. Taylor (1993) stands as a generally accepted and simple form of reaction function description. Given its explanatory powers and rather simplicity in its application over the FED's policy in US, Taylor Rule gained wide recognition (see, e,g, Blinder 1996, Yellen 1996), triggering the motivation to reshape the Rule for other developed countries and also for the developing countries. With these applications, additional explanatory variables had become part of the Taylor Rule, and the literature seems to reach a consensus on the point that "as long as they are not inconsistent with the inflation target in the long run, there can be targets for other variables" (Taylor, 2000).

In this study, we choose to work on a rather simple format and include a lagged independent variable, namely the interest rate in the previous period:

$R_{t}=\beta_{0}+\beta_{1} R_{t-1}+\beta_{2} \pi_{t}+\beta_{3}\left(y_{t}-y *\right)+\varepsilon_{t}$

Here, $R_{t}$ stands for the rate of interest; $\pi_{\mathrm{t}}$ is the inflation rate and $\left(y_{t}-y^{*}\right)$ stands for the output gap. The $\beta$ s are the regression coefficients (policy weights).

In this equation if the coefficient of the lagged interest rate is found positive but still below unity, it represents a partial adjustment of the interest rates to changes in the other macroeconomic variables. When one sees a deviation of output from the potential or inflation from the target, this particular coefficient tells that a "sequence" of moves in the same direction shall take off until deviation turns into convergence. Naturally, $\beta_{1}$ and $\beta_{2}$ show the "overall responsiveness". Hence now we can re-define the terms of interest rate smoothing: high degree of partial adjustment and limited overall responsiveness.

In our econometric work, we have employed monthly macro aggregates from January 2010 to December 2013. We chose 2010 as the beginning of the data set, enabling the impact of newly incorporated financial stability objective on the reaction function. Our data set ends at the latest available spot at the time of writing, that is November 2013. 
We ran our econometric investigation in a dynamic version of the reaction function, seeking the main motive behind the interest rate reaction of the CBRT. Although we constructed the regression analysis on a standard Taylor Rule approach, incorporating the dependent variable with its lag to the right side of the equation will help us to observe the "momentum" from the last period's fund rate change.

We first regress the model in equation (1) to account for the rule of "interest rate smoothing"; that is, the value of $\beta_{1}$. For the interest rate variable, we employed the $\mathrm{O} / \mathrm{N}$ lending rate as the CBRT's policy rate. This rate also corresponds to the upper band of the "interest rate corridor". Foras headline consumer inflation, annual \% change of the consumer price index released by Turkish Statistical Institute (TURKSTAT) is adopted. As we worked with monthly frequency, we employed industrial production to measure the output gap. For this purpose we used the time series adjusted for the calendar and seasonality effects as reported is done by the TURKSTAT. Potential of the series is calculated via the Hodrick Prescott Filter, and thus we obtained the output gap as the difference between the actual industrial production and the potential level. ${ }^{8}$

Regression results are displayed in the first column of Table 1. We find a value of 0.82 for the lagged interest rate variable suggesting a fairly strong smoothing response. The coefficient is statistically significant and the overall model also passes the $f$-statistic for statistical relevance. Both the inflation and output gap variables are of the expected positive sign with significance levels of $10 \%$ and $1 \%$, respectively.

\footnotetext{
${ }^{8}$ We have conducted unit root tests for each of the variables. For the "Inflation" variable with Ho: a=1 (unit root) probability was found to be greater than $5 \%$ and we failed to reject Ho. So in the presence of unit root and nonstationarity, we used the first difference test to obtain stationary series. Output Gap was found to pass the unit root test. "Interest rate": Ho: a $=1$ (unit root) probability was greater than $5 \%$; we failed to reject Ho so with the presence of unit root and we implemented the first difference test to obtain stationarity. The same results were valid for lag values of interest rate in the model. Currency Basket was also s non stationary for the unit root test and its first difference, but it was stationary according to the second difference.
} 


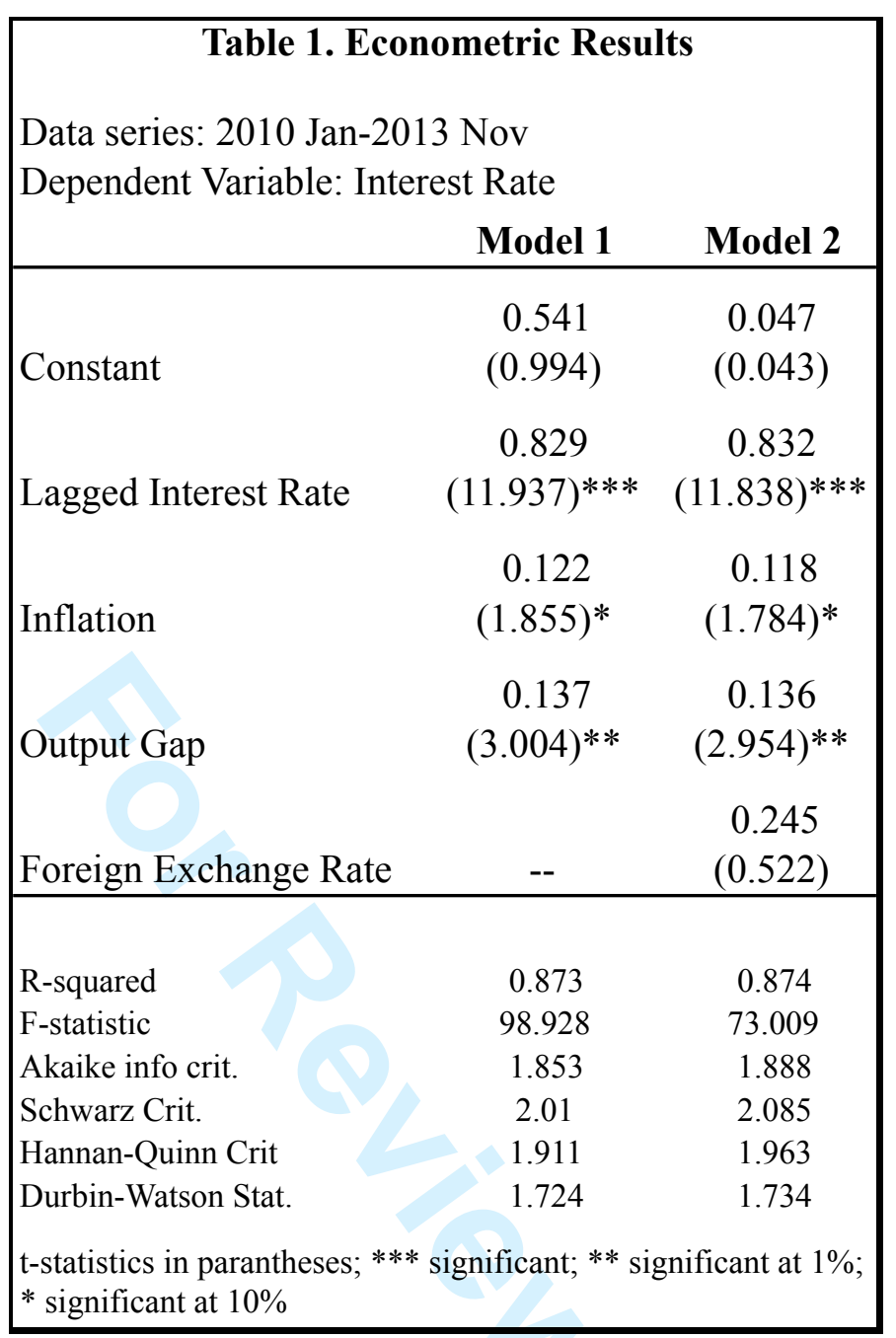

Next, we take the task of the policy responsiveness of the exchange rate on the rate of interest at the margin. For this, we add the foreign exchange currency basket (monthly averages) of the CBRT to the analysis. Results are displayed under the second column in Table 1.

Addition of the exchange rate does not in any way have an impact on the interest-smoothing policy response. The variable has a positive and yet statistically insignificant value with the $R_{t}$. Besides, all the remaining coefficients, in particular the smoothing coefficient $\beta_{l}$, remain almost unaffected. We read these results as preference of the CBRT towards interest smoothing at the expense of exchange rate volatility. Thus, TL is observed to be chosen as the gambit while the Bank seeks interest rate stability. Yet, the fragile short FX position of Turkey's corporate sector and high pass through from currency to the consumer inflation show that excessive volatility in the currency carries the risk of hurting the stability on the output and price dynamics front. Therefore insisting on flat rates with the goal of stability has 
the risk of delivering further instability in times of volatile currency. Indeed, this was the case in late 2011 and early 2014, pushing the CBRT to a sharp and unexpected interest rate hikes.

\section{Conclusion}

This paper is devoted to trace the interest rate smoothing behavior of the Central Bank of the Rep. of Turkey (CBRT) across the "multi objective-multi tool" policy framework that has been instrumental since 2010. Changes in the monetary stance had been almost mandatory within the global recession era that was triggered by the Lehman crisis, in which interest rates were low all around the globe and capital flows to EM were on the rise. Those conditions delivered undesirable consequences for the emerging market economies through the credit channel and Turkey was not the only country that turned towards an "unconventional monetary policy path". Many other developing countries that faced imbalances due to heavy capital flows, employed macro prudential measures within their monetary policy framework while also striving to keep their interest rates low. In fact for many, uncertainties associated with the great recession drove a mandatory break from the macro-prudential regulatory approach, bringing unconventional monetary policy approach on stage.

Taking the transition nature of the Post Lehman era into consideration, we chose to examine the monetary policy approach of the CBRT within a Taylor Rule framework, intentionally standing away from seeking the skeleton of a vague monetary policy rule. Seeing a rather large avenue to explore, our work focused on finding a relevant monetary approach during a transition period that carried high dose of uncertainty thereby directing our work towards the interest rate smoothing literature which invokes "data uncertainty" and "parameter uncertainty".

Our econometric evidence suggests that, over the great recession CBRT maintained an overall stance favoring the interest rate smoothing approach in its discretionary path, and the role of exchange rate on its policy decisions has been statistically insignificant. A Taylor rule summary of the CBRT's actions confirms the interest smoothing view. Yet, sharp policy corrections that came after periods of interest rate smoothing recall the sharp critiques of policy overstaying. Here we check for the CBRT's monetary framework and conclude that it fell short of fulfilling the prerequisites of interest rate smoothing with "weak credibility", "poor communication", and "lack of a well-defined simple monetary framework". Therefore although global macro landscape that was developed with the great recession justifies interest 


\section{References:}

Akcelik, Y., Aysan, A., and Oduncu, A. 2013. "Central banking Making During the PostCrisis World and the Policy Mix of the Central Bank of the Republic of Turkey" Journal of Central Banking: Theory and Practice, 2(1): 5-18.

Aysan, Fendoglu and Kilinc, 2014. "Managing Short-Term Capital Flows in New Central Banking: Unconventional Monetary Policy Framework in Turkey" CBRT Working paper No $14 / 03$.

Bank for International Settlements, 1998. 68th Annual Report, pg:55-75

Benhabib, Jess, Schmitt-Grohe Stephanie. and Uribe Martin 2003, "Backward-Looking Interest Rate Rules, Interest Rate smoothing, and Macroeconomic Instability", Journal of Money Credit and Banking Vol.35, No:6.

Blinder, A.S., 1996. "On the Conceptual Basis of Monetary Policy" Senior Executives Conference of the Mortgage Bankers Association. January 10th, 1996

Caplin, Andrew \& Leahy, John, 1996. "Monetary Policy as a Process of Search," American Economic Review, American Economic Association, vol. 86(4), pages 689-702, September.

Central Bank of Republic of Turkey. 2011. Presentation, 02/2011

Comert, H., Yeldan, E., Olçum, G.A., 2010. "Interest Rate Smoothing and Macroeconomic Instability Under Post-Capital Account Liberalization Turkey" Canadian Journal of Development Studies 31(3-4): 373-396

Csermely, A., Rezessy, A. 2007. "The Theory and Practice of Interest Rate Smoothing" Magyar Nemzeti Bank, MNB Bulletin, November 2007

Degerli, A., and S. Fendoglu, 2013. "Reserve Option mechanism as a Stabilizing Policy tool: Evidence from Exchange Rate Expectations" CBRT Working Paper No 13/28.

Drew, A. and Plantier C.L. 2000, "Interest Rate Smoothing in New Zealand and Other Dollar Bloc Countries", Reserve Bank of New Zealand Discussion Paper Serious No:2000/10.

Fischer, Stanley 2001 “Exchange Rate Regimes: Is the Bipolar View Correct?", Journal of Economic Perspectives, Vol. 15: 3-24.

Helmi, M.H., 2011. "Model in Monetary Policy Rules in the MENA Countries: Issues and Evidences" International Journal of Social Sciences and Humanity Studies, Vol:3, No:2, pg:309-318

Kadioglu, F. 2006. "Parasal Aktarım Mekanizması: Türkiye Örneğinin Yapısal Model Çerçevesinde Analizi” Central Bank of Republic of Turkey, December 2006 
Kara, H. 2012. "Monetary Policy After the Global Crisis" (in Turkish) CBRT Working paper No 12/17.

Lowe, P and Ellis L 1998, "The Smoothing of Official Interest Rates", In Lowe P.(ed). Monetary Policy and Inflation Targeting, Sydney: Reserve Bank of Australia.

Lowe,P., and Ellis, L. 1997. "The Smoothing of Official Interest Rates" Reserve Bank of Australia

Mehra, Y 2001, "The Taylor Principle, Interest Rate Smoothing and Fed Policy in the 1970s and 1980s", Federal Reserve Bank of Richmond, Working Paper No 01-05.

Oduncu, A., Akcelik, Y and Ermisoglu, 2013. "Reserve Option mechanism and FX Volatility" CBRT Working Paper No 2013-03.

Sack, B. 1998a "Does the Fed Act Gradually? A VAR Analysis." Board of Governors of the Federal Reserve System. Finance and Economics Discussion Series, 98-17.

Sack, B. 1998b "Uncertainty, Learning, and Gradual Monetary Policy.” Board of Governors of the Federal Reserve System. Finance and Economics Discussion Series, 98-34.

Sack,B.; Wieland,V. 2000. "Interest Rate Smoothing and Optimal Monetary Policy: A Review of Recent Empirical Evidence" Journal of Economics and Business, 52:205-228

Srour, Gabriel 2001 "Why do Central Banks Smooth Interest Rates", Bank of Canada Working Paper, No 17.

Taylor, J.B., 1993. "Discretion versus Policy Rules in Practice"

Taylor, J.B., 2000. "Recent Developments in the Use of Monetary Policy Rule"

Woodford, M. 2002 “Optimal Interest Rate Smoothing”, Review of Economic Studies, Vol. 70 Issue.4, 861-886.

Yellen, J.L., 1996. Remarks at the National Association of Business Economists, Washington D.C. March 13th, 1996. 